Article

\title{
The Role of Religious Behavior in Health Self-Management: A Community-Based Participatory Research Study
}

\author{
Jane Pfeiffer ${ }^{1, *}$, Hong $\mathrm{Li}^{2}$, Maybelline Martez ${ }^{3}$ and Tim Gillespie ${ }^{4}$ \\ 1 School of Nursing, Azusa Pacific University, 375 Hospitality Lane, San Bernardino, CA 92408, USA \\ 2 School of Nursing, Azusa Pacific University, 901 E. Alosta Ave., Azusa, CA 91702, USA; hli@apu.edu \\ 3 School of Public Health, Loma Linda University, 24951 North Circle Drive, Loma Linda, CA 92350, USA; \\ mmartez@llu.edu \\ 4 CrossWalk Church, 10421 Corporate Drive, Redlands, CA 92374, USA; tim@crosswalkvillage.com \\ * Correspondence: jpfeiffer@apu.edu
}

Received: 18 September 2018; Accepted: 8 November 2018; Published: 13 November 2018

check for updates

\begin{abstract}
Prevalence of chronic disease, mental health problems, and risk behaviors in San Bernardino (SB) County reflect some of the worst health outcomes in the State of California and the United States. Using the Integrated Theory of Health Behavior Change (ITHBC) as the theoretical framework, this community-based participatory research (CBPR) study aimed to determine how religious self-regulation skills and ability, and religious behaviors, jointly affect health promotion behaviors among socio-economically challenged residents of southwest SB County, California. A convenience sample of adult residents $(\mathrm{N}=261)$ completed a series of inventories to measure the relationship between modified ITHBC constructs of religious self-regulation skills, religious self-management behaviors, and health outcomes. Structural Equation Modeling (SEM) analysis was conducted to validate the strong positive effect of religious self-regulation skills and ability on how frequently individuals engage in both organized and non-organized religious activities. Results also indicated a significant positive impact of religious behaviors towards healthy eating behaviors. However, without the engagement in religious activities, high religious self-regulation skills and ability inhibited the likelihood of healthy food intake. This faith-related theoretical model provides an avenue for faith-based organizations' capacity for contributing to community health promotion.
\end{abstract}

Keywords: religious self-regulation; religious self-management behaviors; healthy eating behaviors; health outcomes; religious support; low socio-economic status; organized and non-organized religious behaviors

\section{Introduction}

Multidisciplinary research reveals a range of health benefits through participation in religion (Ansari et al. 2017, p. 6; Koenig et al. 2012; Tan et al. 2013). Religiosity has been associated with health promoting behaviors, such as improved diet, attendance to preventive care, exercise, and moderate drinking, contributing to overall improved health status (Hill and Pargament 2008; Persynaki et al. 2017). Studies also indicate a positive association between religiosity and mental health, including well-being, self-esteem, and decreased stress levels (Krause et al. 2016). The range of health outcomes also involves lowered rates of cardiovascular disease, cancer, hypertension, and blood pressure, all-cause mortality, breast cancer risk factors, and improved fruit and vegetable intake (Gillum and Williams 2009; Gillum and Ingram 2006; Tan et al. 2013). Therefore, this area of research is of great interest among the San Bernardino County population who have higher prevalence rates for heart 
disease and diabetes, compared to neighboring counties and state (San Bernardino County Board of Supervisors 2015). In addition, recent data reveals $38 \%$ of adults in the county were determined to be overweight and 34\% obese (San Bernardino County Board of Supervisors 2015).

This research aims to examine quantitative assessment data of how religious behaviors function as health self-management strategies. The study methodology was developed by the Community-Based Participatory Research (CBPR) approach and the research questions and hypotheses were driven by the Integrated Theory of Health Behavior Change (ITHBC) (Ryan 2009) (See Figure 1 for the modified ITHBC model). Studies of CBPR have found various benefits, which rationalizes its use for this study and includes (1) its ability to support culturally relevant research and incorporate local community knowledge; (2) ability to recruit participants to interventions; (3) development and strengthening skills of the community and academic partners to address difficult issues; (4) productive conflict resolution strategies; (5) promotion of partnership synergy to strengthen collaboration; and (6) continuation of project efforts and sustainability of results beyond the funding period (Jagosh et al. 2015; Israel et al. 2001). Adopting the community-based participatory research approach (CBPR), which is a more desirable model for research with vulnerable populations than traditional research approaches that emphasize less on the context of a phenomenon (Holkup et al. 2004), the current research team sought to determine in what way can the faith community contribute to health status. Such exploration could achieve a balance between research and action that mutually benefits both science and the community, such as the reduction of health disparities. The research question was whether religious self-regulation and religious behaviors can change the individual health behaviors within a community.

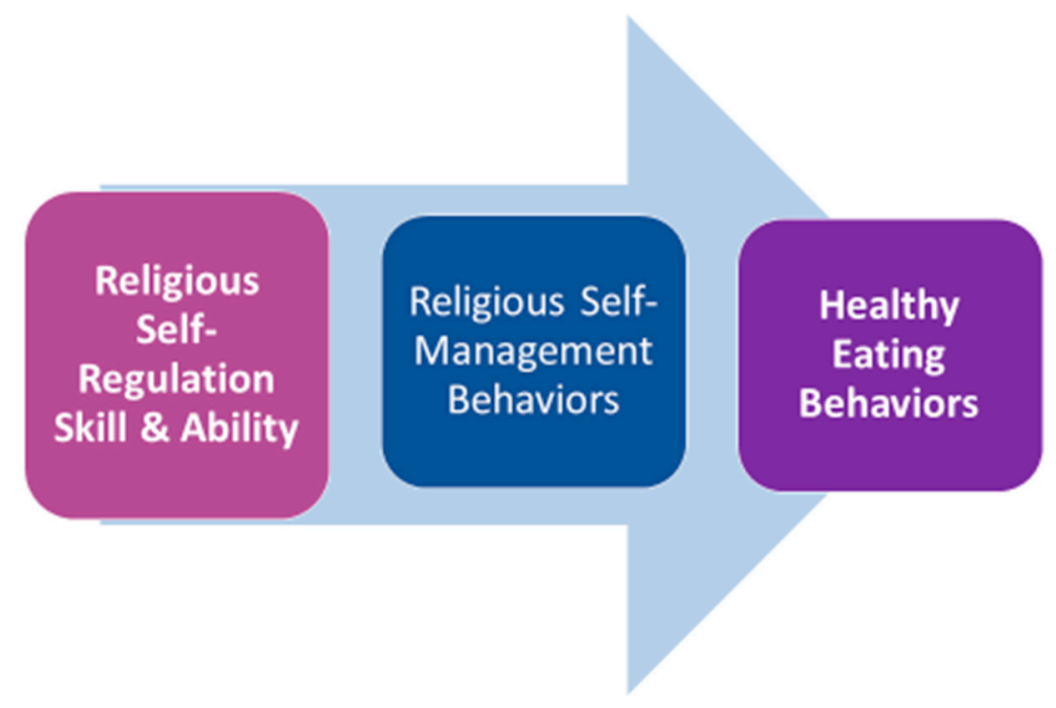

Figure 1. Modified Integrated Theory of Health Behavior Change model.

Before addressing results, a review of recent literature on factors associated with CBPR and health behaviors, including geographical factors, religious self-regulation, intrinsic religiosity, religious coping, religious self-management behaviors, and healthy eating behaviors, is given. Exploration of these constructs will aid in the description of health outcomes affecting at risk communities.

\subsection{Community-Based Participatory Research (CBPR)}

CBPR is an approach to research in public health that involves equitable partnerships and active participation in the decision-making process among community players and researchers to facilitate community health improvement and increase knowledge (Holkup et al. 2004; Jagosh et al. 2015). The CBPR approach has its strengths in sustaining supportive and power-sharing relationships among marginalized groups (Tremblay et al. 2018; Cargo and Mercer 2008; O'Brien and Whitaker 2011). 
Moreover, CBPR has been identified as a successful approach to recruiting and retaining hard to reach participants for research (Israel et al. 2010; De Las Nueces et al. 2012). Through use of this participatory method, concerns of members may be addressed and effective interventions may be set in place to improve health outcomes among the target population.

Key characteristics of CBPR as outlined by (Israel et al. 2010) were used in the design of the research study, including (1) recognition of the community as a unit of identity, (2) development of resources and strengths in the community, (3) encouragement of learning and empowerment that aligns with social inequities, (4) incorporation of knowledge and action for the benefit of all members, (5) furthers the process of collaborative learning and enhances self-efficacy dealing with social inequalities, (6) communicates findings and information acquired to all members, and (7) necessitates a long-standing relationship by all members (Israel et al. 2001). A crucial aspect of successful CBPR involves the effort to build trust among partners and community members to participate equally throughout the research process (Bryan et al. 2014). Through this framework, communities benefit as health disparities are addressed by culturally appropriate interventions and researchers who may facilitate policy change (Israel et al. 2010; Cacari-Stone et al. 2014; O'Brien and Whitaker 2011).

\subsection{Geographical Factors Affecting Health Behavior}

Health behaviors are actions taken by individuals that affect their health and account for up to $40 \%$ of premature deaths in the United States (Saint Onge and Krueger 2017). Public health research reveals that these behaviors are reflective of a variety of social, environmental, and physical contexts (Short and Mollborn 2015). Recent statistics from San Bernardino County relating to these conditions of the built environment reveal an ongoing level of risk due to limited opportunities. For example, the US Census Bureau revealed an increase of San Bernardino County families living in poverty from 12.3\% in 2005 to 16.3\% in 2014 (United States Census Bureau 2014). Most recently, in 2016, the city of San Bernardino specifically had $28.6 \%$ of families living in poverty, the highest rate in the county (San Bernardino County Board of Supervisors 2016).

Additionally, the nutrition environment in San Bernardino has been identified as a "food desert," with a Retail Food Environmental Index (RFEI) of 5.72, indicating a high prevalence of unhealthy food outlets, food deserts, increased obesity, and poor health outcomes in the region (Agboola et al. 2017). Moreover, health disparity trends exist between San Bernardino city and the state of California (Agboola et al. 2017). Specifically, residents of SB city are affected by limited access to fresh produce and instead the presence of more global-chain retail food outlets. Aside from these challenges, public safety is also of great concern in this region. A $43 \%$ increase in San Bernardino gang-related incidents were reported in 2015, compared to the previous year. Also, in the Riverside-San Bernardino area, crime rates are higher than the state and neighboring regions (San Bernardino County Board of Supervisors 2016).

Therefore, developing an intentional outreach intervention is critical to San Bernardino County (SBC) as residents are specifically challenged by "lifestyle" diseases related to aspects of health care, public safety, and environmental concerns affecting their quality of life (San Bernardino County Board of Supervisors 2016). This CBPR assessment study was conducted through close collaboration between the academic institutions, community (i.e., two elementary schools, one community church, and one low income trailer park), and the sponsoring church. The aim was to determine how self-regulation skills and ability, and religious behaviors, jointly affect health promotion behaviors among socio-economically challenged residents of southwestern San Bernardino County.

\subsection{Religious Self-Regulation}

Self-regulation is a process of applying knowledge and beliefs to incorporate a behavior change into one's daily routines and lifestyle. Self-regulation requires an application of knowledge to achieve the preferred, self-chosen goal, and all the self-regulatory thinking and behaviors necessary to achieve the goal. These include "monitoring and reflective thinking, decision making, planning and plan 
enactment, self-evaluation, and management of emotions occurring with the change" (Ryan 2009). Thus, an intrinsic religious commitment or a positive coping that incorporates the divine (God) can assist in applying one's religious knowledge and beliefs involved in these daily decision making processes. Religious self-regulation was defined in this study as religious thinking, experiences, and how one understands and deals with major problems in life (McCullough and Willoughby 2009).

Intrinsic religiosity. Intrinsic religiosity (IR) is described as the degree of religious commitment and the ultimate goal of pursuing and internalizing religion (Koenig and Büssing 2010). Restated intrinsic religiosity assists an individual to integrate personal faith and its meaning and motivation into the daily decisions of life (Allport and Ross 1967). Though there is debate over the internal/external religiosity construct (Hall et al. 2008; Clements et al. 2015) one of the original Hoge (1972) questions for assessing IR ("I try hard to carry my religious beliefs over into all my other dealings in life") was used by Clements et al. (2015) as a single item in the Brief Multidimensional Measurement of Religiousness/Spirituality (BMMR) questionnaire. This question was used to demonstrate concurrent validity in their assessment of Religious Surrender and Attendance. For Religious Surrender, the two items used were "When my understanding of a problem conflicts with God's revelation, I will submit to God's definitions" and "Although I may not see results from my labor, I will continue to implement God's plans as long as God directs me to do so." Attendance was measured by the following question, "How often do you go to religious services?" Thus, IR was measured alongside these three questions among two groups of undergraduate university students and one pregnant women's population from Southern Appalachia, a region known for high religious attendance and health disparities. This, along with two other studies (Hafizi et al. 2015; Mosqueiro et al. 2015) support the positive effects of intrinsic religiosity on diverse groups of patients. Hafizi et al. (2015) also showed the use of Hoge (1972) IR measurement, as validated for use with Farsi-speaking populations in Iran, and inferentially to other Middle Eastern countries. Moreover, findings of Mosqueiro et al. (2015) among primarily white depressed inpatients in the South of Brazil uphold a protective effect of intrinsic religiosity on suicide and psychiatric inpatient admission.

Religious coping. Religious coping became defined as an effort to deal with life stressors through an association with the divine (Mpofu 2018), and it plays an active role in both positive and negative dimensions (Pargament et al. 2011). Specifically, positive religious coping was described as "having a spiritual connectedness with others and a benevolent worldview", whereas negative religious coping recognized tension or spiritual struggle with God (Fincham et al. 2018), Although the impact of the religious dimension of coping mechanisms is generally overlooked in research studies (Fincham et al. 2018), there are promising findings on its specific outcomes on health promotion. Previous research indicates that individuals utilize the expression of religious coping when facing chronic and acute stressors (Cummings and Pargament 2010; Schuster et al. 2001). Recent literature investigating its impact on health outcomes reveal a significant association with improved mental health status (Koenig et al. 1998; Olson et al. 2012), including reduced depression (Abernethy et al. 2002). Moreover, studies of individuals with medical conditions also identify a positive relationship between religious coping and quality of life and reporting of greater physical well-being (Cummings and Pargament 2010; Trevino and McConnell 2014). Similarly, religious coping among youth has also been associated with positive affect and life satisfaction (Van Dyke et al. 2009). Religious coping also holds potential in acting as an alternate strategy to maladaptive eating (Pirutinsky et al. 2012). Furthermore, one study reported that the utilization of religious coping provided an opportunity for African Americans to prevent cardiovascular disease through lowering their blood pressure level (Steffen et al. 2001).

\subsection{Religious Behavior}

Organizational religious activities (ORA). Numerous research studies reveal positive health outcomes among those who frequently attend religious services. For example, religion has been found to aid in stress reduction through coping and allows individuals to engage in healthier lifestyles 
(George et al. 2002; Koenig et al. 1998). Moreover, frequency of church attendance has been positively associated with maintaining good mental health, marital stability, improved social interactions, healthier dietary and physical activity behaviors, reduction of cardiovascular risk, and a suppression effect of obesity (Arredondo et al. 2005; Nam 2013; Oexmann et al. 2001; Strawbridge et al. 2001). The protective effect of religious service attendance against major depression has also been identified in numerous studies (Balbuena et al. 2013; Koenig 2004; Norton et al. 2008; Strawbridge et al. 2001). For example, a $30 \%$ lower odds ratio for lifetime prevalence of depression was reported among those who attended religious services (Maselko et al. 2009). One possible mechanism through which church attendance promotes well-being is that it allows social support, building relationships, and provides participants with a sense of belonging. Religious support can therefore aid in adherence to health programs, seeking help from clergy or church members, and fellowship in stressful events that can reduce negative emotions (Behere et al. 2013).

Non-organizational religious activities (NORA). Although church attendance is one type of organizational religious activity, it promotes private religious behaviors, including prayer and studying scripture (Koenig 1993). Prayer, a type of spiritual activity expressed as words or thoughts addressed to a divine force (Andrade and Radhakrishnan 2009), has also been associated with numerous health benefits. For example, one study revealed that participation in private religious activity, such as prayer or Bible study, was linked to a survival advantage among an elderly community (Helm et al. 2000). In addition, prayer has been associated with a decrease in adverse outcomes among patients suffering from cardiac disease (Çoruh et al. 2005). Intercessory prayer has also been linked to improved success rates of in vitro fertilization, improved immune function, improved rheumatoid arthritis, anxiety reduction, and reduced hospital stay by septic patients (Çoruh et al. 2005).

\subsection{Fast Food Intake}

Diet is an important factor in the development of chronic disease. Recent studies reveal the impact of dietary habits on a variety of cardio metabolic risk factors, such as obesity, glucose-insulin homeostasis, cardiac function, cholesterol, weight-regulation pathways, and the microbiome (Mozaffarian 2016). Evidence-based nutrition research recommends dietary patterns that can improve cardio-metabolic health, such as consumption of fruits, nuts/seeds, vegetables, legumes, whole grains, and yogurt, while reducing intake of red meats, sodium, refined grains, and added sugars (Mozaffarian 2016).

Although these dietary patterns produce cardio-metabolic benefits, they are not accessible in all food environments. For example, low-income neighborhoods struggle with inequitable distribution of healthy foods, indicated by limited access to healthy food sources and yet abundant access to nutrient deficient foods from local fast-food outlets or convenience stores (Hilmers et al. 2012; Zenk et al. 2014). As a result, neighborhood residents who have limited access to supermarkets (vs. convenience stores) have higher rates of obesity and unhealthier eating diets (Larson et al. 2009; Morland and Evenson 2009).

Another contributor to negative health outcomes in at risk populations is the consumption of sugar-sweetened beverages. Recent studies demonstrated that consuming beverages with sucrose and high fructose corn syrup is linked to increased risk of cardiovascular disease, chronic kidney disease, obesity, metabolic syndrome, dental carries, and type 2 diabetes (Bomback et al. 2010; Malik and $\mathrm{Hu}$ 2015; Rosinger et al. 2017). Despite the dire consequences of high-fructose for developing cardio-metabolic diseases, data collected from 2011 to 2014 revealed that $49.3 \%$ of U.S. adults and $62.9 \%$ of youth aged 2 to 19 consumed at least one sweet beverage on a given day (Rosinger et al. 2017). Such a level of sweetened beverage intake also increased calorie intake among these two groups, with approximately $143 \mathrm{kcal}$ for youth and $145 \mathrm{kcal}$ for adults (Rosinger et al. 2017). It is therefore projected that a reduction of sweetened beverage consumption may lower BMI, blood pressure, risk of diabetes, and CHD (Mekonnen et al. 2013). 


\section{Results}

The partnership of faith and health is revealed in the relationship of latent variables (i.e., religious self-regulation skills, religious self-management behaviors, and healthy eating behaviors) identified by use of Structural Equation Modeling (SEM) (see Figure 2 of SEM latent variables). The hypothesized model appears to be a good fit (chi-squared $=15.98, \mathrm{df}=11, p>0.05 ; \mathrm{CFI}=0.99$; RMSEA $=0.042$, $90 \% \mathrm{CI}=[0.000,0.083])$. The factor loadings from all three latent variables to their corresponding measurable variables range from 0.56 to 0.83 . Specifics of measures used are given in the methods section.

One-way straight arrows connecting the three latent variables into a triangle are accompanied with numbers denoting standardized regression coefficients ( $\beta \mathrm{s})$, which can be used as effect size estimates. For purposes of explanation, letters, A, B, and C, are designated to represent the religious self-regulation skills factor, the religious self-management behaviors factor, and the healthy eating behaviors factor, respectively. Thus, the strongly positive effect of $A$ toward $B(\beta=0.81)$ indicates the more religious self-regulation skills one has, the more engagement there is in $B$, religious self-management behaviors. Likewise, the positive effect of $B$ towards $C(\beta=0.86)$ indicates that higher engagement in religious self-management behaviors produces more healthy eating behaviors. However, $\mathrm{A}$ is inversely correlated to $C$, with a strongly negative $A$ toward $C$ effect $(\beta=-0.62)$. The model also indicates religious self-management behaviors serve as a moderating factor for healthy eating behaviors. A total of $26 \%$ variance in healthy eating behaviors is accounted for by this model.

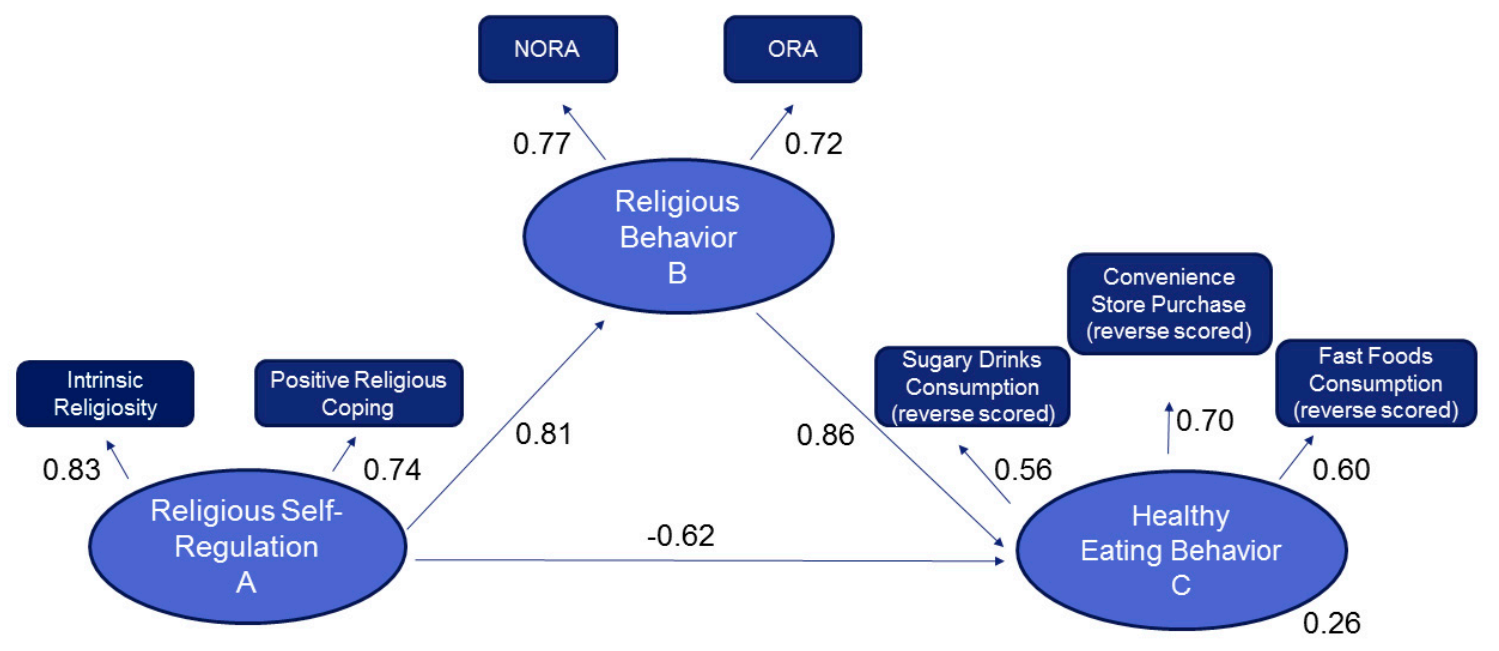

Structural Equation Modeling $(\mathrm{SEM})$ chi-squared $=15.98, \mathrm{df}=11, p>0.05 ; \mathrm{CFI}=$ $0.99 ; \mathrm{RMSEA}=0.042,90 \% \mathrm{Cl}=[0.000,0.083]$

Figure 2. Structural Equation Modeling of latent variables.

\section{Discussion}

Gary Gunderson (1997) describes the mutually enriching role of health and faith in his quote, "Faith needs the language of health in order to understand how it applies to life; health needs the language of faith in order to find its larger context, its meaning" (p. 4). The effect of religious behaviors on healthy eating is not new (Clark et al. 2018; Orlich et al. 2015; Beezhold et al. 2010). However, noting that religious self-regulation is, in part, a matter of perception of both the issue or challenge and the resources to adequately address it for positive health outcomes adds weight to the health and religion interface. The effect of God's people gathered (the church) on healthy eating behaviors is reinforced by the combination of personal religious perceptions, personal commitments to non-organized religious practices (e.g., pray privately, or Bible-reading), and corporate expressions of faith and belief (e.g., worship, service to community, educational offerings). Often privatized religion makes the individual wholly responsible for the being and doing aspects of health and faith. Bringing those individual commitments to the church-gathered allows multiple levels of intellectual, emotional, and spiritual 
support to interact in a synergistic fashion. The Christian church would attribute this support dynamic to the presence and power of the Spirit of God at work with people who gather to pursue God's agenda of love. Gunderson (1997) describes the church and her motivation as people intent on well-being grounded in God and his purposes. He states, "Congregations are where people come together, gathered by God to serve God's intentions of renewing and redeeming the whole world, this is done not in domination, but in love" (emphasis added) (p. 2). Thus, the church intercepts the individualistic pursuit of health and well-being, and acknowledges that health behavior change requires knowledge, support, and self-regulation skills beyond the individual to be successful. While this is not akin to a "Prosperity Gospel", ${ }^{1}$ it is a belief in the abundance of life (John 10:10) as promised by God. This is not financial blessing, but a whole-health perspective. What ancient Jewish tradition would call a life of "Shalom" and Christian adherents would call a life of abundance. Health and wellness are held deeply within this theological tradition, understanding that God is a god who created whole persons, and that health is a key part of living a "whole" life. A community-based participatory research approach can also emphasize the community's responsibility to individuals to change structural aspects of food deserts and unsafe streets for navigating to and from community resources. Without social advocacy, individuals are left encumbered with social determinants of health they cannot change. Yet, this study offers one bright light, one ray of hope for low income, un-resourced, and marginalized neighborhoods; that of partnership with the church, strengthening personal choices in the midst of less than equitable situations.

Community connection, meaningful work, and social relationships are found within the rubric of faith and faith communities. As "eating behavior is strongly influenced by social context" (Higgs and Thomas 2016, p. 1), it would be reasonable to infer that faith and faith communities, those corporate expressions of faith that happen within a particular social context, would add to the increased healthy eating habits of an individual. As well, commonality in lifestyle and belief systems, something that happens in faith communities with shared values and beliefs, may influence healthy eating "because diet similarity among friends and family is most likely when concerns with behaving 'correctly' are high." (ibid).

Those who work in the area of faith understand that the mystery of faith means that there is an indefinable layer of well-being that can be accessed. Christian Scripture calls it "the peace that passes understanding" (Phil. 4:7). In other words, regardless of the situation, peace (well-being) can be obtained by the idea of faith or belief. However, faith is only as valuable as its object, this is why we say we have faith "in" something. When that something or someone is seen as eternal, loving, caring, and unchangeable, there is a unique understanding that somehow works within to create a sense of protection against context.

Without the moderating effect of religious behaviors, religious self-regulation skills appear truncated in their ability to influence healthy eating behaviors. One possible explanation for this comes from Holt et al. $(2003,2015)$. Spiritual health locus of control (SHLOC) concept, which adds active and passive factors distinct from internal and external dimensions of the locus of control. An active SHLOC mindset sees partnership with God and a shared responsibility in the pursuit of health as a daily reality. In contrast, a passive SHLOC understands God to be in control of all things, including one's health. Therefore, it is not necessary to take individual responsibility for any health promoting actions. A more passive SHLOC does not negate the vision of being involved with a higher power nor seeking the support and guidance of this higher power. What it seems not to envision is a personal responsibility related to health behaviors.

Another possible explanation for the strong negative influence of religious self-regulation skills and ability, if without the engagement in religious activities, on healthy eating behaviors lies in the

1 The Prosperity Gospel is the doctrine that God wants people to be prosperous, especially financially; adherents to the Prosperity Gospel believe that wealth is a sign of God's blessing and the poor are poor due to a lack of faith. Koch, Bradley. Journal of Ideology Volume 36, 2014. 
countering epidemiological forces in religion and health. Could crisis religiosity as opposed to resting religiosity determine whether one waits until there is a crisis of health to engage in actively working with God for one's health? (see Hvidt et al. 2017, for full description). Until such time, there may be a restful God-is-in-control belief or a there-is-no-God belief that neither seeks involvement of a higher power nor perceives such involvement as possible, reasonable, or desirable.

Excitingly, this research demonstrates one important promising mechanism to eliminate the potential adverse effect of a God-is-in-control belief on seeking health-promoting eating behavior; that is, taking actions and participating in religious activities at both the individual level and the organizational level. Only when people are willing to do so, will they be able to eat healthier or try to avoid eating unhealthy foods. In sum, the partnership of God and his people demonstrates the strong, positive influence of religious activities on healthy food intake as a proximal health outcome. While a system wide approach would offer a more sustained improvement at the community level, there is still action in which individuals and organizations can engage to make improvements in health. Just as the CBRP approach builds relationships with the community to determine what action is desirable and deemed helpful for the particular community, so can organized and non-organized religious behavior build relationships with God and his people to pursue individual and community health.

Research suggests that faith-based organizations (FBOs) can promote health and well-being both within congregations Caldwell and throughout communities (Ayton et al. 2017). However, faith communities and their leaders, because of their localized context, do not often seek a research- and data-based approach to understanding the needs of their communities. For instance, when a pastor has a congregation of 30-50 people, it is often felt that there is little need for academic evidence to understanding the felt needs of the community. Therefore, faith communities often opt out of a more research oriented methodology to understanding the needs of the communities they serve outside of their congregations. Strategic alignment of initiatives and dollars within the multiple institutions addressing healthcare needs can be a factor when it comes to directing energy to one or more identified health needs within the community. Working in concert, hospitals, churches, not for profits, and academic institutions can use the community health needs assessments, often done by faith-based not-for-profit health systems, as a road map for strategic planning. This alignment in population health strategies results in the betterment of the communities that overlap each entity's service area (Levin 2013; Plunkett et al. 2016).

Future Research Directions: It would seem reasonable to assert that the frequency that one interacts with corporate expressions of faith might have a direct correlation to the efficacy of one's overall health. As well, research to understand the role of increased acceptance into the community could have a positive effect on the trajectory of one's health. One interesting question that warrants further research is whether one specific church outreach model or denomination produces better health behavior than others. For instance, is the health management role of religious behavior more significant when the church is built around a worship-centered model, a social network model, a justice-oriented model, or a combination of these? Also, does the specific health emphasis of a particular denomination have an impact on one's health, as opposed to a faith tradition with less emphasis on personal health? More importantly, future research can focus on the testing of the generalizability of this three-factor model to see to what extent it can be applied to non-religious populations. Moreover, rather than limiting the model to predict or explain healthy eating behavior, future studies could focus on testing the effects of religious self-regulation and behaviors on additional health behavior outcomes, such as smoking, drinking, and exercising, etc. Going to church increases social connection and, therefore, there is less social isolation. Thus, future research could examine the extent to which reduction in social isolation accounts for the associations identified in current research. Lastly, studies which address topics of health disparity, such as cancer screening rates, access to health care, and pre- and post-intervention behavior change, will also clarify what role the church, academic institutions, and community partnerships can have in influencing individual and community health. 


\section{Methods and Materials}

The current study arises from a three-phase, mixed method study conducted within southwestern San Bernardino County, with partners, including a church and two local universities-named removed for blinding and review purposes. The target areas included three specific cities, Loma Linda (zip code 92354), Redlands (zip codes 92373 and 92374), and San Bernardino (zip code 92408). Two of the original research team members (one faculty and one church leader) met with the principal from a local elementary school who assisted in selecting six school parents to form the first pilot focus group. This was conducted in the spring of 2016 at the local elementary school. Masters of public health students conducted the focus group and analyzed the concerns of the community (under review), and reported back to the school administration. The principal initiated a crossing guard, and other school drop off and pick up actions followed. The current research team continued the assessment activity into 2016-17 school year, with recruitment for participation. Principals from both elementary schools and the trailer park administrator cooperated in fliers being sent home in school children's backpack, a phone message sent from one of the principals, and door to door fliers delivered in the trailer park by the primary investigator (P.I.). The church supplied staff support and coordination of office xeroxing of the surveys, and data entry by church members who were also research team members.

The P.I. recruited participants on site at the schools with a table and banner offering free gift cards for participation in the study. Momentum gained as the P.I. met parents at school functions, and was present at 7:30-8:30 a.m. and again at 1:30-2:30 p.m. for drop off and pick up of children at the school. Similarly, a table with a banner was set up twice daily at the trailer park at times recommended by the administrator there, and at one church service chosen by the pastor. At one school, a station was set up with I-pads and surveys loaded online via Qualtrics during their fall festival evening. Here, the research team learned parents much preferred a paper and pencil version of the survey. Thus, data collection from that point forward involved hard copies of the survey.

A convenience sample of adult residents $(\mathrm{N}=261)$ in the target areas participated in the Quantitative Assessment Phase (See Table 1 for Demographic Data). Participants were either parents of children attending two local elementary schools or residents of one community trailer park. The assessment phase involved community engagement strategies, surveys, and focus groups. This article solely reports quantitative findings based on the survey collection. Data collected from focus interviews conducted in 2017 revealed resident concerns regarding environmental stressors, physical safety, mental health, and alcohol and drugs, and will be reported elsewhere.

The survey packet entailed a series of inventories to measure intrinsic religiosity (IR), positive religious coping (PRC), organizational religious activity (ORA), non-organizational religious activity (NORA), as well as three healthy eating indicators. Specifically, IR was measured by the 10-item Intrinsic Religiosity scale (Hoge 1972), a 5-point Likert scale ranging from definitely not true to definitely true of me. A sample question was "My faith involves all of my life." The Cronbach's alpha of IR in this study was 0.77 , indicating a sufficient level of reliability. Positive Religious Coping was measured by the 3-item positive coping subscale of the Brief Religious Coping Scale (Pargament et al. 1988) with a 4-point Likert scale ranging from not at all to a great deal. A sample question was "I think about how my life is part of a larger spiritual force." The Cronbach's alpha of PRC was 0.87 , indicating a good level of reliability. In addition, the frequency of engaging in ORA and NORA was measured using the corresponding questions in the Duke University Religion Index (DUREL) (Koenig et al. 1997). Specifically, respondents were asked to rate how often they attend church or other religious meetings on a 6-point scale ranging from never to more than once per week, and how often they spend time in private religious activities, such as prayer, mediation, or study of scripture, on a 6-point scale ranging from never to more than once a day. Lastly, respondents were asked to report in the previous week how many days they drank at least one sugary drink, how frequently they ate fast food, and how frequently they purchased food from a convenience store, on 3 separate 4-point scales ranging from never to over 5 days. 
Table 1. Demographic data.

\begin{tabular}{lcc}
\hline Demographic Data $\mathbf{N}=\mathbf{2 6 1})$ & $\mathbf{N}$ & $\mathbf{\%}$ \\
\hline Gender-Female & 191 & 74.3 \\
\hline Age-30-49 years & 119 & 46.5 \\
\hline Religious preference & & \\
\hline Christian & 110 & 42.1 \\
Seventh Day Adventist & 48 & 18.3 \\
Catholic & 45 & 17.2 \\
\hline Ethnicity & & \\
\hline Non-Hispanic & 138 & 55.2 \\
Hispanic & 112 & 44.8 \\
\hline Annual income & & \\
\hline$<\$ 30,000$ & 128 & 16.6 \\
\$30,000-<\$50,000 & 38 & 12.8 \\
\$50,000 & 29 & 11.7 \\
\hline Prefer not to answer & 31 & \\
\hline Education & & 44.6 \\
\hline High school degree, GED, or less & 115 & 48.1 \\
\hline Some college, associate, or bachelor's degree & 128 & \\
\hline
\end{tabular}

\section{Conclusions}

This study adds quantitative evidence to support a positive relationship between religious self-regulation skills and abilities and healthy eating behaviors, moderated by the combination of non-organized and organized religious self-management behaviors. This study suggests religiosity as an individual and as a corporate expression of faith offers support for improving a particular public health component, that of healthy eating behaviors. Faith gives purpose and meaning, and in that meaning and purpose is a broader understanding of the trajectory of one's life. In so doing, it is reasonable to think that one would want to be healthier in order fulfill the purpose that is given by the object of that faith.

The impact of a faith community on an individual's life, in relation to healthy eating habits, as seen in this study, is an alert to faith community leaders and coordinators that they have a role to play in this aspect of the lives of their constituents. If social gathering, beliefs, religiosity, and the creation of meaning in people's lives makes a difference, it would behoove faith communities to take the health of the congregants and their community seriously.

The study also demonstrates religious involvement serving as a crucial protective factor for those who identify with God and his people. Faith is always a bit of a mystery, and how faith interacts with the biological processes of any given individual is not known, but the increased health outcomes as related to someone's faith and religiosity suggest that there is an intangible quality that faith brings to an individual that helps them to cope with life in general. Faith is in no way a "fix-all", but does play into one's overall feeling of well-being, purpose, and meaning.

The study also strengthens pursuit of health in community settings by partnership of neighborhoods with the local faith community and surrounding academic institutions. Creating models of Faith, Health, and Community interaction can increase the health outcomes of any community. Research such as this can help to inform the increased health outcomes that can take place through a faith community partnership.

This is especially true when a CBPR approach is used to seek community leadership and ownership of desired changes for improved public health indicators. Rather than waiting for government or community organizations to take action, faith communities can lead the way. When a CBPR approach is used, the data received can be used as a road map to create interventions that addresses the actual needs of a community, rather than a "random acts of kindness" approach to serving the community. As well, the data set can be shared with other community leaders to help align 
the work of multiple entities within the community (Healthcare, Education, Not-for-Profit sectors, community member, and other faith-based organizations) in order to develop a stronger collective impact that will increase the health outcomes of a given population.

Author Contributions: Conceptualization of the study was done by, J.P. and T.G.; Formal analysis by J.P. and H.L.; Investigation by, J.P., M.M. and T.G.; Methodology by, J.P. and T.G.; Project administration, J.P.; Supervision, J.P.; Writing of original draft, J.P., H.L., M.M. and T.G.; Writing - review \& editing, J.P., H.L., M.M. and T.G.

Funding: This research received no external funding.

Conflicts of Interest: The authors declare no conflicts of interest.

\section{References}

Abernethy, Alexis D., H. Theresa Chang, Larry Seidlitz, James S. Evinger, and Paul R. Duberstein. 2002. Religious coping and depression among spouses of people with lung cancer. Psychosomatics 43: 456-63. [CrossRef] [PubMed]

Agboola, Fayomi, R. Patti Herring, Mark Ghamsary, Daniel Handysides, Naomi Modeste, and Keiji Oda. 2017. Enhancing culture of health in food deserts: Reports of a community supported agriculture study in San Bernardino, CA. International Journal of Food Research 4: 1-11.

Allport, Gordon W., and J. Michael Ross. 1967. Personal religious orientation and prejudice. Journal of Personality and Social Psychology 5: 432-43. [CrossRef] [PubMed]

Andrade, Chittaranjan, and Rajiv Radhakrishnan. 2009. Prayer and healing: A medical and scientific perspective on randomized controlled trials. Indian Journal of Psychiatry 51: 247. [CrossRef] [PubMed]

Ansari, Serene, Erica G. Soltero, Elizabeth Lorenzo, and Rebecca E. Lee. 2017. The impact of religiosity on dietary habits and physical activity in minority women participating in the Health is Power (HIP) study. Preventive Medicine Reports 5: 210-13. [CrossRef] [PubMed]

Arredondo, Elva M., John P. Elder, Guadalupe X. Ayala, and Nadia R. Campbell. 2005. Is church attendance associated with Latinas' health practices and self-reported health? American Journal of Health Behavior 29: 502-11. [CrossRef] [PubMed]

Ayton, Darshini, Lenore Manderson, and Ben J. Smith. 2017. Barriers and challenges affecting the contemporary church's engagement in health promotion. Health Promotion Journal of Autrailia 28: 52-58. [CrossRef] [PubMed]

Balbuena, Lloyd, Marilyn Baetz, and Rudy Bowen. 2013. Religious attendance, spirituality, and major depression in Canada: A 14-year follow-up study. The Canadian Journal of Psychiatry 58: 225-32. [CrossRef] [PubMed]

Beezhold, Bonnie L., Carol S. Johnston, and Deanna R. Daigle. 2010. Vegetarian diets are associated with healthy mood states: A cross-sectional study in seventh day adventist adults. Nutrition Journal 9: 26. [CrossRef] [PubMed]

Behere, Prakash B., Anweshak Das, Richa Yadav, and Aniruddh P. Behere. 2013. Religion and mental health. Indian Journal of Psychiatry 55: S187. [CrossRef] [PubMed]

Bomback, Andrew S., Vimal K. Derebail, David A. Shoham, Cheryl A. Anderson, Lyn M. Steffen, Wayne D. Rosamond, and Abhijit V. Kshirsagar. 2010. Sugar-sweetened soda consumption, hyperuricemia, and kidney disease. Kidney International 77: 609-16. [CrossRef] [PubMed]

Bryan, Valerie, Willette Brye, Kenneth Hudson, Leevones Dubose, Shantisha Hansberry, and Martha Arrieta. 2014. Investigating health disparities through community-based participatory research: Lessons learned from a process evaluation. Social Work in Public Health 29: 318-34. [CrossRef] [PubMed]

Cacari-Stone, Lisa, Nina Wallerstein, Analilia P. Garcia, and Meredith Minkler. 2014. The promise of community-based participatory research for health equity: A conceptual model for bridging evidence with policy. American Journal of Public Health 104: 1615-23. [CrossRef] [PubMed]

Cargo, Margaret, and Shawna L. Mercer. 2008. The Value and Challenges of Participatory Research: Strengthening Its Practice. Annual Review of Public Health 29: 325-50. [CrossRef] [PubMed]

Clark, Eddie M., Jin Huang, David L. Roth, Emily Schulz, Beverly R. Williams, and Cheryl L. Holt. 2018. The relationship between religious beliefs and behaviors and changes in spiritual health locus of control over time in a national sample of African Americans. Mental Health, Religion E Culture 20: 449-63. [CrossRef] 
Clements, Andrea D., Tifani R. Fletcher, Natalie A. Cyphers, Anna V. Ermakova, and Beth Bailey. 2015. RSAS-3: Validation of a Very Brief Measure of Religious Commitment for Use in Health Research. Journal of Religion $\mathcal{E}$ Health 54: 134-52. [CrossRef]

Çoruh, Başak, Hana Ayele, Meredith Pugh, and Thomas Mulligan. 2005. Does religious activity improve health outcomes? A critical review of the recent literature. Explore: The Journal of Science and Healing 1: 186-91. [CrossRef] [PubMed]

Cummings, Jeremy P., and Kenneth I. Pargament. 2010. Medicine for the spirit: Religious coping in individuals with medical conditions. Religions 1: 28-53. [CrossRef]

De Las Nueces, Denise, Karen Hacker, Ann DiGirolamo, and LeRoi S. Hicks. 2012. A systematic review of community-based participatory research to enhance clinical trials in racial and ethnic minority groups. Health Services Research 47: 1363-86. [CrossRef] [PubMed]

Fincham, Frank D., Gregory S. Seibert, Ross W. May, Colwick M. Wilson, and Zephon D. Lister. 2018. Religious coping and glycemic control in couples with type 2 diabetes. Journal of Marital and Family Therapy 44: 138-49. [CrossRef] [PubMed]

George, Linda K., Christopher G. Ellison, and David B. Larson. 2002. Explaining the relationships between religious involvement and health. Psychological Inquiry 13: 190-200. [CrossRef]

Gillum, R. Frank, and Deborah D. Ingram. 2006. Frequency of attendance at religious services, hypertension, and blood pressure: The Third National Health and Nutrition Examination Survey. Psychosomatic Medicine 68: 382-85. [CrossRef] [PubMed]

Gillum, Frank, and Carla Williams. 2009. Associations between breast cancer risk factors and religiousness in American women in a national health survey. Journal of Religion and Health 48: 178-88. [CrossRef] [PubMed]

Gunderson, Gary. 1997. Deeply Woven Roots: Improving the Quality of Life in Your Community. Minneapolis: Fortress Press. [CrossRef]

Hafizi, Sina, Harold Koenig, and Doaa Ahmed Khalifa. 2015. Psychometric properties of the Farsi version of Hoge Intrinsic Religiosity Scale in muslims: A brief report. Pastoral Psychology 64: 839-45. [CrossRef]

Hall, Daniel E., Keith G. Meador, and Harold Koenig. 2008. Measuring religiousness in health research: Review and critique. Journal of Religion \& Health 2008: 134-63. [CrossRef]

Helm, Hughes M., Judith C. Hays, Elizabeth P. Flint, Harold G. Koenig, and Dan G. Blazer. 2000. Does private religious activity prolong survival? A six-year follow-up study of 3,851 older adults. The Journals of Gerontology Series A: Biological Sciences and Medical Sciences 55: M400-5. [CrossRef]

Higgs, Suzanne, and Jason Thomas. 2016. Social influences on eating. Current Opinion in Behavioral Sciences 9: 1-6. [CrossRef]

Hill, Peter C., and Kenneth I. Pargament. 2008. Advances in the conceptualization and measurement of religion and spirituality: Implications for physical and mental health research. The American Psychologist 58: 64-74. [CrossRef]

Hilmers, Angela, David C. Hilmers, and Jayna Dave. 2012. Neighborhood disparities in access to healthy foods and their effects on environmental justice. American Journal of Public Health 102: 1644-54. [CrossRef] [PubMed]

Hoge, Dean R. 1972. A validated intrinsic religious motivation scale. Journal for the Scientific Study of Religion 11: 369-76. [CrossRef]

Holkup, Patricia A., Toni Tripp-Reimer, Emily Matt Salois, and Clairann Weinert. 2004. Community-based participatory research: An approach to intervention research within an American Indian community. Advances in Nursing Science 27: 162-75. [CrossRef] [PubMed]

Holt, Cheryl L., Eddie M. Clark, Matthew W. Kreuter, and Doris M. Rubio. 2003. Spiritual health locus of control and breast cancer beliefs among urban African American women. Health Psychology 22: 294-99. [CrossRef] [PubMed]

Holt, Cheryl L., David L. Roth, Jin Huang, and Eddie M. Clark. 2015. Gender differences in the roles of religion and locus of control on alcohol use and smoking among African Americans. Journal of Studies on Alcohol and Drugs 76: 482-92. [CrossRef] [PubMed]

Hvidt, Niels Christian, Dorte Hvidtjørn, Kaare Christensen, Jesper Bo Nielsen, and Jens Søndergaard. 2017. Faith moves mountains-mountains move faith: Two opposite epidemiological forces in research on religion and health. Journal of Religion \& Health 56: 294-304. [CrossRef] 
Israel, Barbara A., Amy J. Schulz, Edith A. Parker, and Adam B. Becker. 2001. Community-based participatory research: Policy recommendations for promoting a partnership approach in health research. Education for Health 14: 182-97. [CrossRef] [PubMed]

Israel, Barbara A., Chris M. Coombe, Rebecca R. Cheezum, Amy J. Schulz, Robert J. McGranaghan, Richard Lichtenstein, Angela G Reyes, Jaye Clement, and Akosua Burris. 2010. Community-based participatory research: A capacity-building approach for policy advocacy aimed at eliminating health disparities. American Journal of Public Health 100: 2094-102. [CrossRef] [PubMed]

Jagosh, Justin, Paula L. Bush, Jon Salsberg, Ann C. Macaulay, Trish Greenhalgh, Geoff Wong, Margaret Cargo, Lawrence W. Green, Carol P. Herbert, and Pierre Pluye. 2015. A realist evaluation of community-based participatory research: Partnership synergy, trust building and related ripple effects. BMC Public Health 15: 725. [CrossRef] [PubMed]

Koenig, Harold G. 1993. Religion and aging. Reviews in Clinical Gerontology 3: 195-203. [CrossRef]

Koenig, Harold G. 2004. Religion, spirituality, and medicine: Research findings and implications for clinical practice. The Southern Medical Journal 97: 1194-200. [CrossRef] [PubMed]

Koenig, Harold G., and Arndt Büssing. 2010. The Duke University Religion Index (DUREL): A five-item measure for use in epidemological studies. Religions 1: 78-85. [CrossRef]

Koenig, Harold, George R. Parkerson Jr., and Keith G. Meador. 1997. Religion index for psychiatric research. The American Journal of Psychiatry 154: 885-86. [CrossRef] [PubMed]

Koenig, Harold G., Kenneth I. Pargament, and Julie Nielsen. 1998. Religious coping and health status in medically ill hospitalized older adults. The Journal of Nervous and Mental Disease 186: 513-21. [CrossRef] [PubMed]

Koenig, Harold, Harold George Koenig, Dana King, and Verna B. Carson. 2012. Handbook of Religion and Health. New York: Oxford University Press.

Krause, Neal, Gail Ironson, and Kenneth I. Pargament. 2016. Spiritual struggles and resting pulse rates: Does strong distress tolerance promote more effective coping? Personality and Individual Differences 98: 261-65. [CrossRef]

Larson, Nicole I., Mary T. Story, and Melissa C. Nelson. 2009. Neighborhood environments: Disparities in access to healthy foods in the US. American Journal of Preventive Medicine 36: 74-81. [CrossRef] [PubMed]

Levin, Jeff. 2013. Engaging the faith community for public health advocacy: An agenda for the Surgeon General. Journal of Religion $\mathcal{E}$ Health 52: 368-85. [CrossRef]

Malik, Vasanti S., and Frank B. Hu. 2015. Fructose and cardiometabolic health: What the evidence from sugar-sweetened beverages tells us. Journal of the American College of Cardiology 66: 1615-24. [CrossRef] [PubMed]

Maselko, Joanna, Stephen E. Gilman, and S. Buka. 2009. Religious service attendance and spiritual well-being are differentially associated with risk of major depression. Psychological Medicine 39: 1009-17. [CrossRef] [PubMed]

McCullough, Michael E., and Brian L. B. Willoughby. 2009. Religion, self-regulation, and self-control: Associations, explanations, and implications. Psychological Bulletin 135: 69. [CrossRef] [PubMed]

Mekonnen, Tekeshe A., Michelle C. Odden, Pamela G. Coxson, David Guzman, James Lightwood, Y. Claire Wang, and Kirsten Bibbins-Domingo. 2013. Health benefits of reducing sugar-sweetened beverage intake in high risk populations of California: Results from the cardiovascular disease (CVD) policy model. PLoS ONE 8: e81723. [CrossRef] [PubMed]

Morland, Kimberly B., and Kelly R. Evenson. 2009. Obesity prevalence and the local food environment. Health $\mathcal{E}$ Place 15: 491-95. [CrossRef]

Mosqueiro, Bruno Paz, Neusa Sica de Rocha, and Marcelo Pio de Almeida Fleck. 2015. Intrinsic Religiosity, Resilience, Quality of Life, and Suicide Risk in Depressed Inpatients. Journal of Affective Disorders 179: 128-33. [CrossRef] [PubMed]

Mozaffarian, Dariush. 2016. Dietary and policy priorities for cardiovascular disease, diabetes, and obesity: A comprehensive review. Circulation 133: 187-225. [CrossRef] [PubMed]

Mpofu, Elias. 2018. How religion frames health norms: A structural theory approach. Religions 9: 119. [CrossRef]

Nam, Sanggon. 2013. The effects of religious attendance and obesity on health by race/ethnicity. Osong Public Health and Research Perspectives 4: 81-88. [CrossRef] [PubMed]

Norton, Maria C., Archana Singh, Ingmar Skoog, Christopher Corcoran, JoAnn T. Tschanz, Peter P. Zandi, John C. S. Breitner, Kathleen A. Welsh-Bohmer, and David C. Steffens. 2008. Church attendance and new episodes of 
major depression in a community study of older adults: The Cache County Study. The Journals of Gerontology Series B: Psychological Sciences and Social Sciences 63: P129-37. [CrossRef]

O'Brien, Matthew J., and Robert C. Whitaker. 2011. The role of community-based participatory research to inform local health policy: A case study. Journal of General Internal Medicine 26: 1498-501. [CrossRef] [PubMed]

Oexmann, Mary J., Rhoda Ascanio, and Brent M. Egan. 2001. Efficacy of a Church-Based Intervention on Cardiovascular risk Reduction. Ethnicity \& Disease 11: 817-22.

Olson, Michael M., Dorothy B. Trevino, Jenenne A. Geske, and Harold Vanderpool. 2012. Religious coping and mental health outcomes: An exploratory study of socioeconomically disadvantaged patients. Explore: The Journal of Science and Healing 8: 172-76. [CrossRef] [PubMed]

Orlich, Michael J., Pramil N. Singh, Joan Sabaté, Jing Fan, Lars Sveen, Hannelore Bennett, Synnove F. Knutsen, W. Lawrence Beeson, Karen Jaceldo-Siegl, and Terry L. Butler. 2015. Vegetarian dietary patterns and the risk of colorectal cancers. JAMA Internal Medicine 175: 767-76. [CrossRef] [PubMed]

Pargament, Kenneth I., Joseph Kennell, William Hathaway, Nancy Grevengoed, Jon Newman, and Wendy Jones. 1988. Religion and the problem-solving process: Three styles of coping. Journal for the Scientific Study of Religion, 90-104. [CrossRef]

Pargament, Kenneth, Margaret Feuille, and Donna Burdzy. 2011. The Brief RCOPE: Current psychometric status of a short measure of religious coping. Religions 2: 51-76. [CrossRef]

Persynaki, Angeliki, Spyridon Karras, and Claude Pichard. 2017. Unraveling the metabolic health benefits of fasting related to religious beliefs: A narrative review. Nutrition 35: 14-20. [CrossRef] [PubMed]

Pirutinsky, Steven, David H. Rosmarin, and Cheryl L. Holt. 2012. Religious coping moderates the relationship between emotional functioning and obesity. Health Psychology 31: 394. [CrossRef] [PubMed]

Plunkett, Robyn, Barbara Leipert, and Joanne Olson. 2016. Exploring the influence of social determinants, social capital, and health expertise on health and the rural church. Journal of Holistic Nursing 34: 236-43. [CrossRef] [PubMed]

Rosinger, Asher, Kirsten Herrick, Jaime Gahche, and Sohyun Park. 2017. Sugar-Sweetened Beverage Consumption among US Youth, 2011-2014. NCHS Data Brief. Number 271. National Center for Health Statistics. Available online: https: / www.cdc.gov/nchs/data/databriefs/db271.pdf (accessed on 13 April 2018).

Ryan, Polly. 2009. Integrated theory of health behavior change: Background and intervention development. Clinical Nurse Specialist 23: 161. [CrossRef] [PubMed]

Saint Onge, Jarron M., and Patrick M. Krueger. 2017. Health lifestyle behaviors among US adults. SSM-Population Health 3: 89-98. [CrossRef] [PubMed]

San Bernardino County Board of Supervisors. 2015. Community Indicators Report 2015. Edited by San Bernardino Board of Supervisors. San Bernardino, California. Available online: http://cms.sbcounty.gov/portals/21/ resources\%20documents/cir_2015_report.pdf (accessed on 20 April 2018).

San Bernardino County Board of Supervisors. 2016. Commnity Indicators Report 2016. Edited by San Bernardino Board of Supervisors. San Bernardino, California. Available online: http://cms.sbcounty.gov/Portals/21/ Resources\%20Documents/SB_2016_REPORT.ONLINE\%20bookmarked.pdf?ver=2017-05-11-102049-407 (accessed on 20 April 2018).

Schuster, Mark A., Bradley D. Stein, Lisa H. Jaycox, Rebecca L. Collins, Grant N. Marshall, Marc N. Elliott, Annie J. Zhou, David E. Kanouse, Janina L. Morrison, and Sandra H. Berry. 2001. A national survey of stress reactions after the September 11, 2001, terrorist attacks. New England Journal of Medicine 345: 1507-12. [CrossRef] [PubMed]

Short, Susan E., and Stefanie Mollborn. 2015. Social determinants and health behaviors: Conceptual frames and empirical advances. Current Opinion in Psychology 5: 78-84. [CrossRef] [PubMed]

Steffen, Patrick R., Alan L. Hinderliter, James A. Blumenthal, and Andrew Sherwood. 2001. Religious coping, ethnicity, and ambulatory blood pressure. Psychosomatic Medicine 63: 523-30. [CrossRef] [PubMed]

Strawbridge, William J., Sarah J. Shema, Richard D. Cohen, and George A. Kaplan. 2001. Religious attendance increases survival by improving and maintaining good health behaviors, mental health, and social relationships. Annals of Behavioral Medicine 23: 68-74. [CrossRef] [PubMed]

Tan, Min-Min, Carina K. Y. Chan, and Daniel D. Reidpath. 2013. Religiosity and spirituality and the intake of fruit, vegetable, and fat: A systematic review. Evidence-Based Complementary and Alternative Medicine 2013. [CrossRef] [PubMed] 
Tremblay, Marie-Claude, Debbie H. Martin, Alex M. McComber, Amelia McGregor, and Ann C. Macaulay. 2018. Understanding Community-Based Participatory Research through a Social Movement Framework: A Case Study of the Kahnawake Schools Diabetes Prevention Project. BMC Public Health 18: 487. [CrossRef] [PubMed]

Trevino, Kelly M., and Timothy R. McConnell. 2014. Religiosity and Religious Coping in Patients with Cardiovascular Disease: Change over Time and Associations with Illness Adjustment. Journal of Religion and Health 53: 1907-17. [CrossRef] [PubMed]

United States Census Bureau. 2014. San Bernardino County, California. Available online: https:/ /www.census. gov/quickfacts/fact/table/sanbernardinocountycalifornia/AFN120212 (accessed on 28 April 2018).

Van Dyke, Cydney J., David S. Glenwick, John J. Cecero, and Se-Kang Kim. 2009. The relationship of religious coping and spirituality to adjustment and psychological distress in urban early adolescents. Mental Health, Religion and Culture 12: 369-83. [CrossRef]

Zenk, Shannon N., Lisa M. Powell, Leah Rimkus, Zeynep Isgor, Dianne C. Barker, Punam Ohri-Vachaspati, and Frank Chaloupka. 2014. Relative and absolute availability of healthier food and beverage alternatives across communities in the United States. American Journal of Public Health 104: 2170-78. [CrossRef] [PubMed]

(C) 2018 by the authors. Licensee MDPI, Basel, Switzerland. This article is an open access article distributed under the terms and conditions of the Creative Commons Attribution (CC BY) license (http:/ / creativecommons.org/licenses/by/4.0/). 